\title{
FRACIONAMENTO, DESSORÇÃO E EXTRAÇÃO QUÍMICA DE ZINCO EM LATOSSOLOS ${ }^{(1)}$
}

\author{
C. W. A. NASCIMENTO(2), R. L. F. FONTES ${ }^{(3)}$, \\ J.C. L. NEVES ${ }^{(3)} \&$ A. C. F. D. MELÍCIO(4)
}

\begin{abstract}
RESUMO
O conhecimento das formas químicas do Zn no solo, bem como de suas relações com os teores disponíveis para as plantas, é importante para a previsão do comportamento desse micronutriente. Este trabalho teve como objetivo estudar a influência da calagem e de doses de Zn sobre a dessorção, extração e fracionamento desse elemento em amostras de seis Latossolos. As amostras, com e sem calagem, receberam 0,20 e $40 \mathrm{mg} \mathrm{dm}^{-3}$ de Zn e foram incubadas por 30 dias. Após a incubação, foram determinados os teores de $\mathrm{Zn}$ pelos extratores Mehlich-1, Mehlich-3, DTPA e EDTA. Os teores de Zn foram determinados nas frações: trocável, matéria orgânica, óxido de manganês, óxido de ferro amorfo e óxido de ferro cristalino, residual, além dos teores totais. A dessorção foi avaliada mediante extrações sucessivas com resina de troca catiônica. Com a aplicação de Zn, esse elemento foi retido, principalmente, nas frações trocável e matéria orgânica. A calagem provocou drástica redução nos teores de Zn trocável e aumento nas frações: matéria orgânica, óxidos de ferro amorfo e cristalino e óxidos de manganês. Nos solos sem calagem, todos os extratores correlacionaramse significativamente com a fração Zn trocável, enquanto, nos solos com calagem, essa correlação foi significativa com o Zn na fração orgânica. Nos solos sem calagem, o teor de $\mathrm{Zn}$ dessorvido das frações decresceu na seguinte ordem: trocável = matéria orgânica > óxido de manganês > óxido de ferro amorfo $>$ óxido de ferro cristalino, com os extratores EDTA, Mehlich-1 e Mehlich-3, apresentando as melhores correlações com o total dessorvido. A calagem provocou ausência de dessorção para o Zn
\end{abstract}

Termos de indexação: micronutrientes, calagem, análise de solo.

(1) Recebido para publicação em outubro de 2001 e aprovado em abril de 2002.

(2) Professor do Departamento de Agronomia, Universidade Federal Rural de Pernambuco - UFRPe. Rua Dom manuel de Medeiros s/n, Dois Irmãos, CEP 52171-900 Recife (PE). E-mail: cwan@bol.com.br

(3) Professor do Departamento de Solos, Universidade Federal de Viçosa - UFV. Av. PH Rolfs s/n, CEP 36571-000 Viçosa (MG). E-mail: renildes@solos.ufv.br

(4) Acadêmico de Agronomia, UFV. Bolsista CNPq/PIBIC. 


\title{
SUMMARY: FRACTIONING, DESORPTION, AND CHEMICAL EXTRACTION OF ZINC FROM OXISOLS
}

\begin{abstract}
Knowledge of the chemical forms of $\mathrm{Zn}$ in the soil and the relationships with soil available concentrations are important for predicting its behavior. This work aimed to study the influence of zinc on the desorption, extraction and fractioning of $\mathrm{Zn}$ in samples from six Oxisols. Thesoil samples, with and without limeapplication, werekept incubated for 30 days after receiving $\mathrm{Zn}$ doses $\left(0.0,20\right.$, and $\left.40 \mathrm{mg} \mathrm{dm}^{-3}\right)$. After incubation, the micronutrient was extracted with Mehlich-1, Mehlich-3, DTPA and EDTA. Additionally, the samples werefractionated for Zn determination in thefractions: exchangeable, organic matter, manganese oxides, amorphous iron oxides, crystalline iron oxides, and residual fraction, as well as the total concentrations of the micronutrient. The micronutrient desorption was evaluated by successive extractions with cation exchange resin. It was concluded that, without liming, theapplication of the $\mathrm{n}$ doses to thesoil resulted in retention of $\mathrm{Zn}$ mainly in the exchangeableand organic matter fractions. In general, liming reduced the exchangeable contents and increased organic matter, amorphous and crystalline iron, and manganeseoxidefractions. Without liming, $\mathrm{Zn}$ in theexchangeablefraction was highly correlated with all extractors. With liming, all extractors presented high correlation with $\mathrm{Zn}$ in the organic matter fraction. Without liming, $\mathrm{Zn}$ lability in thefractions decreased in the order: $\mathrm{Ex}=\mathrm{OM}>\mathrm{MnOx}>\mathrm{AFeOx}>>\mathrm{CF}$ eOx, for EDTA. Mehlich-1, and Mehlich-3, presented best corre ations with thetotal desorbed zincamounts, whileliming caused absence of $\mathrm{Zn}$ desorption.
\end{abstract}

Index terms: Micronutrients, liming, soil analysis.

\section{NTRODUÇÃO}

Os teores dezinco em sol os têm sido medi dos por meio de extrações químicas simples. No entanto, como a quantidade do mi cronutriente extraída varia com o extrator, essas extrações têm apresentado graus variados de sucesso para diagnose de deficiência ou de toxidez desse elemento para as plantas.

A disponibilidade de $\mathrm{Zn}$ indicada por extratores químicos pode ser associada à distribuição desse micronutriente nas frações. Segundo Zhu \& Alva (1993), a identificação das formas nas quais os micronutrientes dos solos são extraídos pelos diferentes métodos de extração pode ajudar a entender a eficiência de cada método. No processo de fracionamento, a amostra de solo é tratada, seqüencialmente, com diferentes reagentes, visando determinar a concentração do Zn em cada uma das frações.

Estudando a disponibilidade de Zn para milho, I yengar et al. (1981) encontraram que sua absorção variou diretamente com as frações solúvel, adsorvida, ligada à matéria orgânica eresidual e, inversamente, com as frações ligadas a óxidos de Fe, Al e Mn e com o pH dos solos. Oliveira et al. (1999) concluíram que a fração trocável foi a principal responsável pela quantidade de Zn obtida pel os extratores Mehlich-1, Mehlich-3, $\mathrm{HCl} 1 \mathrm{~mol} \mathrm{~L}^{-1}$ e DTPA em amostras de 12 solos.
Aceita-se, geralmente, que as concentrações de Zn na solução do solo e, conseqüentemente, a disponibilidade para as plantas são controladas por reações de sorção-dessorção (Harter, 1991). Embora numerosos estudos tenham examinado a adsorção de Zn em solos, pou cos têm-se dedicado ao processo reverso: dessor ção do el emento.

A calagem pode prejudicar a dessorção de Zn, por ser a sorção mais reversível a val ores baixos de $\mathrm{pH}$. I sso ocorre porque as ligações de complexação monodentadas podem modificar-se para ligações bidentadas com o aumento do pH (McBride, 1994) ou pelo fato de o $\mathrm{Zn}$ hidrolisar-se quando o pH é el evado, aumentado, assim, a taxa de adsorção específica pela adsorção preferencial da forma $\mathrm{ZnOH}^{+}($Alloway, 1990)

Este trabalho teve o objetivo de estudar a influência da calagem e de doses de zinco sobre a dessorção, extração química e fracionamento desse elemento em amostras de L atossolos.

\section{MATERIAL E MÉTODOS}

Foram col etadas amostras de seis sol os (0-20 m), selecionados de acordo com teores diferentes de argila e de matéria orgânica (Quadro 1), os quais foram classificados como Latossolo Vermelho - LV1 (Sete Lagoas), Latossolo Vermelho - LV2 (São 
Sebastião do Paraíso), LatossoloVermel ho - LV3 (São Sebastião do Paraíso), Latossolo Vermel ho-Amarelo - LVA1 (J oãoPinheiro), LatossoloVermel ho-Amarelo - LVA2 (Viçosa) e Latossolo Vermel ho-Amarelo húmico - LVA3 (Viçosa).

As amostras dos solos foram homogeneizadas e passadas por peneira de $2,0 \mathrm{~mm}$ de malha e separadas em subamostras de $600 \mathrm{~cm}^{3}$ para aplicação dos tratamentos. Metade das amostras teve sua acidez corrigida para pH na faixa de 6,57,0. Feita a adição do corretivo, as amostras foram mantidas úmidas à capacidade de campo por um período de 15 dias; após esse período, receber am três doses de $\mathrm{Zn}$ e permaneceram incubadas, por um período de 30 dias, com umidade mantida próxima à capacidade de campo. O zinco foi aplicado aos solos, em solução, na forma de $\mathrm{ZnCl}_{2}$, nas doses de 0, 20 e $40 \mathrm{mg} \mathrm{dm}^{-3}$ de Zn.

Após a incubação, foram determinados os teores de Zn após extração com Mehlich-1 (De Filippo \& Ribeiro, 1997), Mehlich-3 (Mehlich, 1984), DTPA (Lindsay \& Norvell, 1978) e EDTA (Lantmann \& Meurer, 1982).

As amostras dos sol os foram extraídas seqüencialmente, segundo método de Shuman (1985), com exceção da fração óxido de ferro amorfo obtida pelo método de Chao \& Zhou (1983). Essefracionamento separou o Zn nas frações: trocável, ligada à matéria orgânica, óxido de manganês, óxido de ferro amorfo e óxido de ferro cristalino. Os teores totais foram obtidos por digestãoácida de acordo com Ure (1990). A fração residual foi considerada a diferença entre os teores totais e a soma das frações anteriores.
Para avaliar a dessorção, uma mesma amostra de solo foi submetida a extrações sucessivas utilizando resina catiônica. Essa técnica possibilita dessorver praticamente toda a forma lábil desse elemento no solo e, desse modo, quantificar o teor que poderia estar disponível às plantas em condições de cultivo. Foi utilizada uma resina trocadora de cátions, fortemente ácida, em forma de lâmina, nas dimensões de 5,0 X 2,0 cm, saturada por $\mathrm{NaHCO}_{3}$.

Cada amostra desolo ( $3 \mathrm{~g}$ ) com a lâmina de resina e $30 \mathrm{~mL}$ de água destilada foi submetida à agitação horizontal (150 rpm) em tubo decentrífuga de $50 \mathrm{~mL}$ por um período de $16 \mathrm{~h}$. Após, a resina foi retirada, lavada em água destilada com pisseta, colocada em $40 \mathrm{~mL}$ de solução extratora de $\mathrm{HCl} 1 \mathrm{~mol} \mathrm{~L}^{-1}$ eagitada por $2 \mathrm{~h}$. As extrações sucessivas foram efetuadas até que a concentração do micronutriente atingisse um patamar de pequenas variações e, portanto, não houvesse dessorção adicional de Zn do solo.

\section{RESULTADOS E DISCUSSÃO}

As concentrações de $Z n$ nas frações, bem como o Zn total, variaram amplamente, conforme os solos, as doses e o $\mathrm{pH}$ (Quadro 2). Os teores iniciais de $\mathrm{Zn}$ total, na dosezero de Zn, para os seis sol os variaram de 11,8 (LVA2) a 115,0 $\mathrm{mg} \mathrm{kg}^{-1}$ (LV3). Esses valores estão relacionados com o material de origem, sendo encontrados maiores teores nos sol os originários de rochas máficas (LV1, LV2 eLV3) e menores naqueles derivados de granitos ou gnaisses (LVA1, LVA2, LVA3).

Quadro 1. Caracterização química e física das amostras de solos provenientes de Sete Lagoas (LV1), São Sebastião do Paraíso (LV2 e LV3), J oão Pinheiro (LVA1) e Viçosa (LVA2 e LVA3)

\begin{tabular}{|c|c|c|c|c|c|c|}
\hline Característica & LV1 & LV2 & LV3 & LVA1 & LVA2 & LVA3 \\
\hline $\mathrm{pH} \mathrm{H}_{2} \mathrm{O}(1: 2,5)$ & 4,6 & 4,4 & 4,7 & 4,0 & 4,1 & 4,2 \\
\hline $\mathrm{P}\left(\mathrm{mg} \mathrm{dm}^{-3}\right)^{(1)}$ & 4,0 & 0,0 & 0,0 & 1,3 & 0,0 & 1,9 \\
\hline $\mathrm{K}\left(\mathrm{mg} \mathrm{dm} \mathrm{m}^{-3}\right)^{(1)}$ & 20 & 59 & 16 & 21 & 15 & 15 \\
\hline $\mathrm{Ca}^{2+}\left(\mathrm{cmol}_{\mathrm{c}} \mathrm{dm}^{-3}\right)^{(2)}$ & 1,24 & 0,55 & 0,72 & 0,08 & 0,02 & 0,46 \\
\hline $\mathrm{Mg}^{2+}\left(\mathrm{cmol}_{\mathrm{c}} \mathrm{dm}^{-3}\right)^{(2)}$ & 0,20 & 0,11 & 0,23 & 0,04 & 0,02 & 0,13 \\
\hline $\mathrm{Al}^{3+}\left(\mathrm{cmol}_{\mathrm{c}} \mathrm{dm}^{-3}\right)^{(2)}$ & 0,50 & 0,10 & 0,20 & 0,90 & 1,20 & 1,90 \\
\hline $\mathrm{H}+\mathrm{Al}\left(\mathrm{cmol}_{\mathrm{c}} \mathrm{dm}^{-3}\right)^{(3)}$ & 8,3 & 11,9 & 6,6 & 6,6 & 8,9 & 7,6 \\
\hline CTC $C_{\text {efetiva }}\left(\mathrm{cmol}_{\mathrm{c}} \mathrm{dm}^{-3}\right)$ & 2,45 & 0,91 & 1,19 & 1,07 & 1,28 & 2,53 \\
\hline $\mathrm{CTC}_{\text {total }}\left(\mathrm{cmol}_{\mathrm{c}} \mathrm{dm}^{-3}\right)$ & 10,25 & 12,71 & 7,59 & 6,77 & 8,98 & 8,23 \\
\hline$V(\%)$ & 14,5 & 6,4 & 13,0 & 2,5 & 0,87 & 7,7 \\
\hline m (\%) & 20,4 & 11,0 & 16,8 & 84,1 & 93,81 & 75,1 \\
\hline C.O. $\left(\mathrm{g} \mathrm{kg}^{-1}\right)$ & 28,7 & 13,9 & 17,0 & 8,7 & 18,6 & 112,5 \\
\hline P-rem (mg L-1) (5) & 7,48 & 3,61 & 6,54 & 28,65 & 2,76 & 1,34 \\
\hline Areia grossa $\left(\mathrm{g} \mathrm{kg}^{-1}\right)^{(6)}$ & 110 & 70 & 90 & 400 & 150 & 460 \\
\hline Areia fina $\left(\mathrm{g} \mathrm{kg}^{-1}\right)^{(6)}$ & 40 & 230 & 300 & 230 & 100 & 140 \\
\hline Silte $\left(\mathrm{g} \mathrm{kg}^{-1}\right)^{(6)}$ & 140 & 240 & 190 & 50 & 70 & 160 \\
\hline Argila $\left(\mathrm{g} \mathrm{kg}^{-1}\right)^{(6)}$ & 710 & 460 & 420 & 320 & 680 & 240 \\
\hline
\end{tabular}

(1) Mehlich-1. (2) $\mathrm{KCl} 1 \mathrm{~mol} \mathrm{~L}{ }^{-1}$. (3) CaOAc 0,5 mol L-1. (4) Walkley-Black (De Filippo \& Ribeiro, 1997). (5) Alvarez V. et al. (2000).

(6) EMBRAPA (1997). 
Nos solos em condições naturais, o $\mathrm{Zn}$ foi encontrado principalmente na forma residual (71 a $98 \%$ ) e em óxidos de ferro cristalino (1 a $13 \%$ ), exceção feita ao LVA3, que, pel o seu el evado teor de matéria orgânica, apresenta uma concentração de Zn ligada a essa fraçãoligeiramentesuperior à retida pelos óxidos de ferro cristalinos. Esses resultados estão em concordância com os apresentados por outros autores (Shuman, 1985; Xiang et al., 1995) e indicam baixa disponibilidade de Zn graças à sua ligação em formas al tamenteestáveis, de difícil acesso pelas raízes das plantas. Para essas condições, as frações consideradas mais disponíveis representam pouco em relação ao Zn total, com val ores médi os de 1 \% para a fração trocável, e de $4 \%$, para o Zn complexado na matéria orgânica.

Com o aumento da dose de $Z n$ aplicada nos solos sem calagem, esseelementofoi retidoprincipalmente em formas trocáveis e na matéria orgânica, mantendo-se lábil no período do ensaio. Em solos ácidos, como também observado por Xiang et al. (1995), a fração trocável está relacionada com a

Quadro 2. Concentrações de zinco nas frações: trocável (Tr), matéria orgânica (MO), óxido de manganês (OxMn), óxido de ferro amorfo (OxFeA), óxido de ferro cristalino (OxFeC), residual (R), total (T) e percentagem relativa em cada uma dessas frações em relação ao total, para três doses de zinco e duas de calagem

\begin{tabular}{|c|c|c|c|c|c|c|c|c|c|c|c|c|c|c|}
\hline \multirow[t]{2}{*}{ Solo } & \multirow{2}{*}{$\begin{array}{c}\text { Dose } \\
\mathrm{mg} \mathrm{dm}^{-3}\end{array}$} & \multicolumn{2}{|c|}{$\operatorname{Tr}$} & \multicolumn{2}{|c|}{ MO } & \multicolumn{2}{|c|}{ OxMn } & \multicolumn{2}{|c|}{ OxFeA } & \multicolumn{2}{|c|}{ OxFeC } & \multicolumn{2}{|l|}{$\mathbf{R}$} & \multirow{2}{*}{$\frac{\mathbf{T}}{\mathrm{mg} \mathrm{kg}^{-1}}$} \\
\hline & & $\mathrm{mg} \mathrm{kg}^{-1}$ & $\%$ & $\mathrm{mg} \mathrm{kg}^{-1}$ & $\%$ & $\mathrm{mg} \mathrm{kg}^{-1}$ & $\%$ & $\mathrm{mg} \mathrm{kg}^{-1}$ & $\%$ & $\mathrm{mg} \mathrm{kg}^{-1}$ & $\%$ & $\mathrm{mg} \mathrm{kg}^{-1}$ & $\%$ & \\
\hline \multicolumn{15}{|c|}{ Sem calagem } \\
\hline LV1 & $\begin{array}{r}0 \\
20 \\
40\end{array}$ & $\begin{array}{r}0,0 \\
5,5 \\
14,9\end{array}$ & $\begin{array}{r}0 \\
7 \\
15\end{array}$ & $\begin{array}{r}1,1 \\
13,7 \\
21,5\end{array}$ & $\begin{array}{r}2 \\
18 \\
22\end{array}$ & $\begin{array}{l}0,2 \\
0,9 \\
1,5\end{array}$ & $\begin{array}{l}0 \\
1 \\
1\end{array}$ & $\begin{array}{l}0,5 \\
1,5 \\
2,0\end{array}$ & $\begin{array}{l}1 \\
2 \\
2\end{array}$ & $\begin{array}{l}1,7 \\
2,3 \\
2,1\end{array}$ & $\begin{array}{l}3 \\
3 \\
2\end{array}$ & $\begin{array}{l}54,8 \\
53,9 \\
56,3\end{array}$ & $\begin{array}{l}94 \\
69 \\
57\end{array}$ & $\begin{array}{l}58,2 \\
77,9 \\
98,3\end{array}$ \\
\hline LV2 & $\begin{array}{r}0 \\
20 \\
40\end{array}$ & $\begin{array}{r}0,0 \\
6,5 \\
17,8\end{array}$ & $\begin{array}{r}0 \\
6 \\
13\end{array}$ & $\begin{array}{r}0,2 \\
7,1 \\
11,1\end{array}$ & $\begin{array}{l}0 \\
6 \\
8\end{array}$ & $\begin{array}{l}0,0 \\
0,9 \\
1,6\end{array}$ & $\begin{array}{l}0 \\
1 \\
1\end{array}$ & $\begin{array}{l}0,2 \\
0,6 \\
0,8\end{array}$ & $\begin{array}{l}0 \\
1 \\
1\end{array}$ & $\begin{array}{l}1,9 \\
1,5 \\
1,5\end{array}$ & $\begin{array}{l}2 \\
1 \\
1\end{array}$ & $\begin{array}{r}102,1 \\
97,7 \\
105,6\end{array}$ & $\begin{array}{l}98 \\
85 \\
76\end{array}$ & $\begin{array}{l}104,4 \\
114,4 \\
138,5\end{array}$ \\
\hline LV3 & $\begin{array}{r}0 \\
20 \\
40\end{array}$ & $\begin{array}{r}0,2 \\
7,6 \\
19,3\end{array}$ & $\begin{array}{r}0 \\
5 \\
14\end{array}$ & $\begin{array}{r}1,4 \\
12,1 \\
15,5\end{array}$ & $\begin{array}{r}1 \\
9 \\
11\end{array}$ & $\begin{array}{l}0,2 \\
0,6 \\
1,1\end{array}$ & $\begin{array}{l}0 \\
0 \\
1\end{array}$ & $\begin{array}{l}0,1 \\
0,6 \\
0,8\end{array}$ & $\begin{array}{l}0 \\
0 \\
1\end{array}$ & $\begin{array}{l}1,0 \\
0,9 \\
1,0\end{array}$ & $\begin{array}{l}1 \\
1 \\
1\end{array}$ & $\begin{array}{l}112,1 \\
116,5 \\
105,1\end{array}$ & $\begin{array}{l}97 \\
84 \\
74\end{array}$ & $\begin{array}{l}115,0 \\
138,3 \\
142,9\end{array}$ \\
\hline LVA1 & $\begin{array}{r}0 \\
20 \\
40\end{array}$ & $\begin{array}{r}0,2 \\
14,0 \\
27,8\end{array}$ & $\begin{array}{r}1 \\
39 \\
48\end{array}$ & $\begin{array}{r}0,6 \\
6,8 \\
10,4\end{array}$ & $\begin{array}{r}5 \\
19 \\
18\end{array}$ & $\begin{array}{l}0,0 \\
0,3 \\
1,0\end{array}$ & $\begin{array}{l}0 \\
1 \\
2\end{array}$ & $\begin{array}{l}0,2 \\
0,3 \\
0,5\end{array}$ & $\begin{array}{l}1 \\
1 \\
1\end{array}$ & $\begin{array}{l}1,7 \\
2,4 \\
1,6\end{array}$ & $\begin{array}{r}13 \\
7 \\
3\end{array}$ & $\begin{array}{l}10,2 \\
11,8 \\
16,7\end{array}$ & $\begin{array}{l}80 \\
33 \\
29\end{array}$ & $\begin{array}{l}12,9 \\
35,7 \\
58,1\end{array}$ \\
\hline LVA2 & $\begin{array}{r}0 \\
20 \\
40\end{array}$ & $\begin{array}{r}0,1 \\
7,9 \\
19,9\end{array}$ & $\begin{array}{r}1 \\
29 \\
27\end{array}$ & $\begin{array}{r}0,8 \\
10,6 \\
18,4\end{array}$ & $\begin{array}{r}7 \\
38 \\
25\end{array}$ & $\begin{array}{l}0,3 \\
1,0 \\
1,3\end{array}$ & $\begin{array}{l}2 \\
3 \\
2\end{array}$ & $\begin{array}{l}0,2 \\
0,9 \\
1,4\end{array}$ & $\begin{array}{l}2 \\
3 \\
2\end{array}$ & $\begin{array}{l}1,5 \\
2,2 \\
2,6\end{array}$ & $\begin{array}{r}12 \\
8 \\
3\end{array}$ & $\begin{array}{r}8,9 \\
5,2 \\
26,3\end{array}$ & $\begin{array}{l}76 \\
19 \\
36\end{array}$ & $\begin{array}{l}11,8 \\
27,8 \\
73,7\end{array}$ \\
\hline LVA3 & $\begin{array}{r}0 \\
20 \\
40\end{array}$ & $\begin{array}{r}0,7 \\
17,3 \\
43,5\end{array}$ & $\begin{array}{r}4 \\
26 \\
33\end{array}$ & $\begin{array}{r}1,9 \\
26,1 \\
59,4\end{array}$ & $\begin{array}{l}10 \\
39 \\
45\end{array}$ & $\begin{array}{l}0,3 \\
1,9 \\
3,3\end{array}$ & $\begin{array}{l}1 \\
3 \\
3\end{array}$ & $\begin{array}{l}0,8 \\
2,7 \\
4,6\end{array}$ & $\begin{array}{l}4 \\
4 \\
4\end{array}$ & $\begin{array}{l}1,6 \\
1,9 \\
2,3\end{array}$ & $\begin{array}{l}8 \\
3 \\
2\end{array}$ & $\begin{array}{l}14,3 \\
17,5 \\
18,6\end{array}$ & $\begin{array}{l}71 \\
26 \\
14\end{array}$ & $\begin{array}{r}20,1 \\
67,4 \\
131,8\end{array}$ \\
\hline Média & & 11,3 & 15 & 12,2 & 16 & 0,9 & 1 & 1,0 & 1 & 1,8 & 4 & 51,9 & 62 & 79,3 \\
\hline C.V. (\%) & & 6,0 & & 5,1 & & 15,6 & & 12,9 & & 8,8 & & 5,1 & & 4,1 \\
\hline \multicolumn{15}{|c|}{ Com calagem } \\
\hline LV1 & $\begin{array}{r}0 \\
20 \\
40\end{array}$ & $\begin{array}{l}0,0 \\
0,0 \\
0,4\end{array}$ & $\begin{array}{l}0 \\
0 \\
0\end{array}$ & $\begin{array}{r}0,8 \\
7,5 \\
18,6\end{array}$ & $\begin{array}{r}1 \\
10 \\
19\end{array}$ & $\begin{array}{l}0,1 \\
3,2 \\
6,8\end{array}$ & $\begin{array}{l}0 \\
4 \\
7\end{array}$ & $\begin{array}{l}0,6 \\
4,8 \\
8,4\end{array}$ & $\begin{array}{l}1 \\
6 \\
9\end{array}$ & $\begin{array}{l}1,5 \\
2,0 \\
4,4\end{array}$ & $\begin{array}{l}3 \\
3 \\
4\end{array}$ & $\begin{array}{l}55,2 \\
60,4 \\
59,7\end{array}$ & $\begin{array}{l}95 \\
78 \\
61\end{array}$ & $\begin{array}{l}58,2 \\
77,9 \\
98,3\end{array}$ \\
\hline LV2 & $\begin{array}{r}0 \\
20 \\
40\end{array}$ & $\begin{array}{l}0,0 \\
0,0 \\
0,0\end{array}$ & $\begin{array}{l}0 \\
0 \\
0\end{array}$ & $\begin{array}{r}0,1 \\
10,3 \\
20,2\end{array}$ & $\begin{array}{r}0 \\
9 \\
15\end{array}$ & $\begin{array}{l}0,2 \\
4,6 \\
9,5\end{array}$ & $\begin{array}{l}0 \\
4 \\
7\end{array}$ & $\begin{array}{l}0,2 \\
1,4 \\
2,4\end{array}$ & $\begin{array}{l}0 \\
1 \\
2\end{array}$ & $\begin{array}{l}0,7 \\
0,7 \\
0,7\end{array}$ & $\begin{array}{l}1 \\
1 \\
1\end{array}$ & $\begin{array}{r}103,2 \\
97,4 \\
105,7\end{array}$ & $\begin{array}{l}99 \\
85 \\
76\end{array}$ & $\begin{array}{l}104,4 \\
114,4 \\
138,5\end{array}$ \\
\hline LV3 & $\begin{array}{r}0 \\
20 \\
40\end{array}$ & $\begin{array}{l}0,0 \\
1,2 \\
3,3\end{array}$ & $\begin{array}{l}0 \\
1 \\
2\end{array}$ & $\begin{array}{r}1,1 \\
17,2 \\
32,6\end{array}$ & $\begin{array}{r}1 \\
12 \\
23\end{array}$ & $\begin{array}{l}0,0 \\
2,1 \\
3,9\end{array}$ & $\begin{array}{l}0 \\
2 \\
3\end{array}$ & $\begin{array}{l}0,0 \\
0,6 \\
1,1\end{array}$ & $\begin{array}{l}0 \\
0 \\
1\end{array}$ & $\begin{array}{l}0,5 \\
0,7 \\
0,5\end{array}$ & $\begin{array}{l}0 \\
1 \\
0\end{array}$ & $\begin{array}{l}113,4 \\
116,5 \\
101,5\end{array}$ & $\begin{array}{l}99 \\
84 \\
71\end{array}$ & $\begin{array}{l}115,0 \\
138,3 \\
142,9\end{array}$ \\
\hline LVA1 & $\begin{array}{r}0 \\
20 \\
40\end{array}$ & $\begin{array}{l}0,2 \\
0,2 \\
0,2\end{array}$ & $\begin{array}{l}2 \\
1 \\
0\end{array}$ & $\begin{array}{r}1,1 \\
20,1 \\
39,2\end{array}$ & $\begin{array}{r}9 \\
56 \\
67\end{array}$ & $\begin{array}{l}0,3 \\
1,1 \\
1,5\end{array}$ & $\begin{array}{l}2 \\
3 \\
3\end{array}$ & $\begin{array}{l}0,2 \\
1,2 \\
1,8\end{array}$ & $\begin{array}{l}2 \\
3 \\
3\end{array}$ & $\begin{array}{l}0,6 \\
0,8 \\
0,9\end{array}$ & $\begin{array}{l}5 \\
2 \\
2\end{array}$ & $\begin{array}{l}10,5 \\
12,3 \\
14,5\end{array}$ & $\begin{array}{l}81 \\
34 \\
25\end{array}$ & $\begin{array}{l}12,9 \\
35,7 \\
58,1\end{array}$ \\
\hline LVA2 & $\begin{array}{r}0 \\
20 \\
40\end{array}$ & $\begin{array}{l}0,1 \\
0,7 \\
2,0\end{array}$ & $\begin{array}{l}1 \\
3 \\
3\end{array}$ & $\begin{array}{r}0,1 \\
6,8 \\
15,9\end{array}$ & $\begin{array}{r}1 \\
24 \\
22\end{array}$ & $\begin{array}{l}0,0 \\
3,3 \\
6,8\end{array}$ & $\begin{array}{r}0 \\
12 \\
9\end{array}$ & $\begin{array}{l}0,2 \\
3,7 \\
6,3\end{array}$ & $\begin{array}{r}1 \\
13 \\
9\end{array}$ & $\begin{array}{l}0,5 \\
4,0 \\
5,5\end{array}$ & $\begin{array}{r}3 \\
14 \\
7\end{array}$ & $\begin{array}{r}13,8 \\
9,3 \\
37,2\end{array}$ & $\begin{array}{l}94 \\
33 \\
50\end{array}$ & $\begin{array}{l}14,7 \\
27,8 \\
73,7\end{array}$ \\
\hline LVA3 & $\begin{array}{r}0 \\
20 \\
40\end{array}$ & $\begin{array}{l}0,0 \\
1,2 \\
3,4\end{array}$ & $\begin{array}{l}0 \\
2 \\
3\end{array}$ & $\begin{array}{r}2,2 \\
15,8 \\
33,2\end{array}$ & $\begin{array}{l}11 \\
23 \\
25\end{array}$ & $\begin{array}{l}0,2 \\
3,5 \\
6,7\end{array}$ & $\begin{array}{l}1 \\
5 \\
5\end{array}$ & $\begin{array}{r}1,3 \\
15,9 \\
26,7\end{array}$ & $\begin{array}{r}6 \\
24 \\
20\end{array}$ & $\begin{array}{r}1,7 \\
6,6 \\
10,0\end{array}$ & $\begin{array}{r}8 \\
10 \\
8\end{array}$ & $\begin{array}{l}14,7 \\
24,4 \\
51,8\end{array}$ & $\begin{array}{l}73 \\
36 \\
39\end{array}$ & $\begin{array}{r}20,1 \\
67,4 \\
131,8\end{array}$ \\
\hline Média & & 0,7 & 1 & 13,5 & 18 & 3,0 & 4 & 4,3 & 6 & 2,4 & 4 & 55,6 & 67 & 79,3 \\
\hline C.V. (\%) & & 3,3 & & 5,6 & & 9,5 & & 7,4 & & 8,2 & & 7,1 & & 4,1 \\
\hline
\end{tabular}


disponibilidade de Zn, ea sua transformação para a fração orgânica, por exemplo, pode ser importante para reduzir a toxidez de $\mathrm{Zn}$ para as plantas. $\mathrm{Na}$ presença da calagem, mesmo na mais alta dose, ocorreu drástica redução na fração trocável e aumento do Zn retido pela matéria orgânica e pelos óxidos. Decréscimos similares na fração trocável com o aumento do $\mathrm{pH}$, associados a alterações no Zn complexado na matéria orgânica ou ligado a óxidos foram também observados em outros trabalhos (Sims \& Patrick, 1978; l yengar et al., 1981).

A elevação do $\mathrm{pH}$ pela calagem provocou incremento médio percentual de 4 a 6 vezes no $Z n$ adsorvido, respectivamente, pelos óxidos de manganês e de ferro amorfo, provavelmente em virtude de adsorção específica, o que confirma a relação entre óxidos, reação do solo e passagem do Zn para formas não-lábeis (Cavallaro \& McBride, 1984; Harter, 1991). Xiang et al. (1995) reportaram aumentos semelhantes nos teores de $\mathrm{Zn}$ ligado a óxidos de ferro cristalinos e amorfos em solos com reação al cal ina comparativamente a sol os áci dos.

No presente trabalho, o aumento médio na adsorção de Zn pelos óxidos de ferro cristalinos com a calagem foi inexpressivo e, para alguns solos, menor que o obtido na ausência da calagem. Segundo Okazaki et al. (1986), a retenção de íons metálicos por superfícies de óxidos é inversamente dependente do grau de cristalinidade e, por causa das cargas variáveis dos óxidos, dependente do pH.

Outro fator a ser considerado na retenção do Zn pelas frações é tempo de reação com o solo. Segundo Barrow (1993), um maior tempo fará com que o Zn passe para formas mais estáveis na presença de óxidos cristalinos, pois a reação pode continuar lentamente com a difusão dos íons adsorvidos para o interior das partículas. Essa tendência pode ser observada no quadro 2 nos sol os sem calagem e dose 0 de $Z n$, nos quais os teores de Zn na forma de óxido de ferro cristalino foram, em geral, mai ores que no solo com adição deZn. Ma \& U ren (1997) encontraram que o $\mathrm{Zn}$ adicionado em ensaios de longa duração (5-20 anos) encontrava-se, predominantemente, ligado às formas de óxidos de ferro e de alumínio, enquanto para o Zn, recentemente adicionado (30 a 360 dias), os mai ores teores foram encontrados nas formas mais reativas (trocável e solúvel em água). Esse resultado demonstra a importância do tempo nas transformações do $\mathrm{Zn}$ adicionado aos solos e indica que, em solos cultivados e fertilizados com $\mathrm{Zn}$, o efeito resi dual do fertilizante decresce com seu tempo de residência no solo, sendo esse efeito incrementado pela calagem.

A matéria orgânica foi a principal responsável pela retenção de Zn nos sol os submeti dos à calagem, retendo até $67 \%$ do $\mathrm{Zn}$ total, com valor médio de $18 \%$ para o conjunto de sol os edoses. O importante papel da matéria orgânica na complexação do Zn, quando o pH é aumentado, tem sido demonstrado por outros autores (J effrey \& Uren, 1983; Sims, 1986) e deve-se, basicamente, às reações de hidrólise que envol vem a formação de espécies monoméricas desse elemento com o aumento do pH e à ionização de grupos carboxílicos e fenólicos presentes em substâncias húmicas (Stevenson, 1991). Como observado por Shuman (1988), teores mais elevados de matéria orgânica no solo podem ajudar a amenizar o decréscimo em solubilidade dos micronutrientes catiônicos como resultado de altos valores de $\mathrm{pH}$.

Os teores de Zn nas três doses, nos solos sem calagem, foram maiores com os extratores ácidos Mehlich-1 e Mehlich-3, seguidos pelos agentes quelantes EDTA e DTPA (Quadro 3). Para os sol os com calagem, foi observada a mesma tendência, com exceção do EDTA, que passou a extrair concentrações do elemento próximas às obtidas pelo Mehlich-3.

Segundo os resultados, o extrator DTPA foi o que apresentou maior sensibilidade à mudança de $\mathrm{pH}$, semel hantemente aos resultados obtidos por Abreu \& Raij (1997) e Menezes (1998). Os extratores Mehlich-1 e EDTA não foram sensíveis à mudança na disponibilidade de $Z n$ decorrente de modificação da reação do solo. Nesse particular, o extrator Mehlich-1 tem recebido diversas críticas quanto à possibilidade de extrair formas de nutrientes nãodisponíveis ligados a sítios de adsorção específica e, em decorrência de sua acidez el evada, extrair Zn ligado a hidróxidos e carbonatos e, portanto, nãodisponíveis às plantas, o que limitaria sua aplicabilidade em sol os ácidos. Quanto ao EDTA, é possível quea concentração utilizada neste trabalho e por outros autores (Lantman \& Meurer, 1982; Bataglia \& Raij, 1994) seja muito elevada, principalmente para sol os com baixos teores de $Z n$, com perda de sensibilidade em relação às mudanças de $\mathrm{pH}$. Há, também, a possibilidade de extração de formas não-disponíveis do Zn em virtude da el evada concentração do complexante, inclusive pela dissolução de óxidos de ferro (Borggaard, 1979).

As correlações entre os teores obtidos pelos extratores e as frações de Zn diminuem na ordem da seqüência do fracionamento, o queédesejável, visto que, na mesma ordem, decresce a biodisponibilidade. Para o Zn disponível nos solos sem calagem, as melhores correlações foram obtidas para as seguintes frações: trocável, óxido de manganês e matéria orgânica, não havendo correlação com a fração óxido de ferro cristalino para os quatro extratores (Quadro 4).

Nos solos com calagem, todos os extratores apresentaram dimi nuição de correlação com a fração trocável e aumento com a fração matéria orgânica. Com a calagem, no entanto, a transferência de Zn ocorreu tanto para a fração matéria orgânica quanto para os óxidos de ferro amorfos (Quadro 2), sendo essa transferência mais bem detectada peloMehlich-3 e DTPA; o método Mehlich-3 apresentou, ainda, a 
melhor correlação com a fração matéria orgânica, principal responsável pelo reservatório de Zn nos solos submetidos à calagem. Zhu \& Alva (1993) encontraram correlação alta entre o Zn ligado à matéria orgânica e o extraído pelo Mehlich-1 e Mehlich-3, enquanto LeClaire et al. (1984) reportaram estreita correlação entre o Zn extraído pelo DTPA e a soma da fração solúvel e matéria orgânica.

Quadro 3. Zinco extraído por Mehlich-1, Mehlich-3, DTPA e EDTA de amostras de seis solos de Minas Gerais em três doses do micronutriente e duas de calagem

\section{Solo Dose Mehlich-1 Mehlich-3 DTPA EDTA}

\begin{tabular}{|c|c|c|c|c|c|}
\hline \multicolumn{6}{|c|}{$m g d^{-3}$} \\
\hline \multicolumn{6}{|c|}{ Sem calagem } \\
\hline LV1 & $\begin{array}{r}0,0 \\
20,0 \\
40,0\end{array}$ & $\begin{array}{r}1,46 \\
16,59 \\
30,81\end{array}$ & $\begin{array}{r}0,26 \\
11,27 \\
24,54\end{array}$ & $\begin{array}{r}0,29 \\
6,59 \\
16,75\end{array}$ & $\begin{array}{r}0,33 \\
7,62 \\
15,18\end{array}$ \\
\hline LV2 & $\begin{array}{r}0,0 \\
20,0 \\
40,0\end{array}$ & $\begin{array}{r}0,77 \\
16,20 \\
34,56\end{array}$ & $\begin{array}{r}0,00 \\
11,74 \\
25,93\end{array}$ & $\begin{array}{r}0,05 \\
8,30 \\
22,37\end{array}$ & $\begin{array}{r}0,13 \\
9,77 \\
21,46\end{array}$ \\
\hline LV3 & $\begin{array}{r}0,0 \\
20,0 \\
40,0\end{array}$ & $\begin{array}{r}0,71 \\
21,84 \\
43,62\end{array}$ & $\begin{array}{r}0,00 \\
13,98 \\
25,86\end{array}$ & $\begin{array}{r}0,13 \\
10,14 \\
24,84\end{array}$ & $\begin{array}{r}0,18 \\
13,03 \\
30,38\end{array}$ \\
\hline LVA1 & $\begin{array}{r}0,0 \\
20,0 \\
40,0\end{array}$ & $\begin{array}{r}1,22 \\
23,28 \\
41,30\end{array}$ & $\begin{array}{r}0,09 \\
17,89 \\
39,85\end{array}$ & $\begin{array}{r}0,34 \\
13,89 \\
33,29\end{array}$ & $\begin{array}{r}0,24 \\
15,02 \\
31,01\end{array}$ \\
\hline LVA2 & $\begin{array}{r}0,0 \\
20,0 \\
40,0\end{array}$ & $\begin{array}{r}0,70 \\
17,01 \\
33,24\end{array}$ & $\begin{array}{r}0,00 \\
9,56 \\
23,16\end{array}$ & $\begin{array}{r}0,06 \\
8,33 \\
21,00\end{array}$ & $\begin{array}{r}0,02 \\
10,35 \\
20,29\end{array}$ \\
\hline LVA3 & $\begin{array}{r}0,0 \\
20,0 \\
40,0\end{array}$ & $\begin{array}{r}2,75 \\
30,52 \\
54,17\end{array}$ & $\begin{array}{r}0,53 \\
21,36 \\
39,51\end{array}$ & $\begin{array}{r}0,85 \\
12,10 \\
29,26\end{array}$ & $\begin{array}{r}1,19 \\
19,24 \\
38,92\end{array}$ \\
\hline Média & & 20,60 & 14,75 & 11,59 & 13,02 \\
\hline C.V. (\%) & & 5,95 & 7,69 & 11,61 & 6,80 \\
\hline \multicolumn{6}{|c|}{ Com calagem } \\
\hline LV1 & $\begin{array}{r}0,0 \\
20,0 \\
40,0\end{array}$ & $\begin{array}{r}1,51 \\
16,33 \\
32,01\end{array}$ & $\begin{array}{r}0,17 \\
9,70 \\
22,34\end{array}$ & $\begin{array}{r}0,33 \\
6,10 \\
14,99\end{array}$ & $\begin{array}{r}0,90 \\
10,56 \\
20,55\end{array}$ \\
\hline LV2 & $\begin{array}{r}0,0 \\
20,0 \\
40,0\end{array}$ & $\begin{array}{r}0,88 \\
18,59 \\
36,33\end{array}$ & $\begin{array}{r}0,78 \\
9,90 \\
20,39\end{array}$ & $\begin{array}{r}0,00 \\
5,44 \\
15,63\end{array}$ & $\begin{array}{r}0,54 \\
11,87 \\
27,15\end{array}$ \\
\hline LV3 & $\begin{array}{r}0,0 \\
20,0 \\
40,0\end{array}$ & $\begin{array}{r}0,87 \\
21,60 \\
41,08\end{array}$ & $\begin{array}{r}0,00 \\
11,77 \\
27,16\end{array}$ & $\begin{array}{r}0,01 \\
7,70 \\
21,79\end{array}$ & $\begin{array}{r}0,36 \\
11,21 \\
25,58\end{array}$ \\
\hline LVAI & $\begin{array}{r}0,0 \\
20,0 \\
40,0\end{array}$ & $\begin{array}{r}2,31 \\
22,42 \\
42,05\end{array}$ & $\begin{array}{r}0,93 \\
16,00 \\
31,85\end{array}$ & $\begin{array}{r}0,25 \\
9,77 \\
17,32\end{array}$ & $\begin{array}{r}1,00 \\
15,56 \\
35,85\end{array}$ \\
\hline LVA2 & $\begin{array}{r}0,0 \\
20,0 \\
40,0\end{array}$ & $\begin{array}{r}0,64 \\
16,21 \\
33,55\end{array}$ & $\begin{array}{r}0,00 \\
10,21 \\
17,92\end{array}$ & $\begin{array}{r}0,00 \\
3,99 \\
10,85\end{array}$ & $\begin{array}{r}0,32 \\
7,51 \\
13,87\end{array}$ \\
\hline LVA3 & $\begin{array}{r}0,0 \\
20,0 \\
40,0\end{array}$ & $\begin{array}{r}2,09 \\
29,98 \\
43,93\end{array}$ & $\begin{array}{r}0,70 \\
18,54 \\
35,75\end{array}$ & $\begin{array}{r}0,92 \\
16,39 \\
34,40\end{array}$ & $\begin{array}{r}1,77 \\
21,10 \\
44,94\end{array}$ \\
\hline Média & & 20,13 & 13,01 & 9,21 & 13,92 \\
\hline C.V. (\%) & & 5,88 & 13,14 & 13,51 & 9,40 \\
\hline
\end{tabular}

Os dados médios para solos e doses de Zn, sem calagem (Quadro 3), mostram que a quantidade de Zn extraída por Mehlich-1 e Mehlich-3 foi superior à obtida para a fração matéria orgânica (Quadro 2). Por outro lado, para os extratores quelantes, DTPA e EDTA, essas quantidades foram inferiores ou muito próximas, sugerindo possível competição entre esses extratores e a matéria orgânica pela complexação do micronutriente. Foi observado decréscimonoteor deZn extraído por DTPA para solos com maiores teores de carbono orgânico (LV1 e LVA3), relativamente ao Zn encontrado na fração matéria orgânica, tal como observado por Narwal \& Singh (1998). Esses autores sugeriram que o Zn forma complexos estáveis com a matéria orgânica, o que reduz a capacidade de extração do micronutriente pelo DTPA naquelas condições.

Para os sol os sem calagem, os maiores teores de Zn dessorvido, para todas as doses e períodos de dessorção, for am obti dos para os sol os LVA3, LVA2 e LVA1 (Figura 1); os dois primeiros apresentaram a maior parte do $\mathrm{Zn}$ retido nas frações trocável e matéria orgânica (Quadro 2). Os menores teores dessorvidos ocorreram nos sol os LV2, LV1 eLV3 que apresentaram menores teores de $\mathrm{Zn}$ adsorvido a essas frações. De modo geral, há uma indicação de que a fração matéria orgânica seja a principal responsável pelo fornecimento de $\mathrm{Zn}$ à solução. As concentrações de $Z n$ recuperadas pela resina aumentaram com a dose aplicada, sendo mai ores no LVA3, solo com maior teor de carbono orgânico, o que demonstra a capacidade da matéria orgânica em suprir Zn para a solução e indica que a maior parte do elemento ligado a essa fração encontra-se na forma lábil. As correlações significativas obtidas entre as frações de Zn e o total dessorvido desse elemento revelam a seguinte ordem de labilidade dessas frações: trocável $(0,93)=$ matéria orgânica $(0,93)>$ óxido de manganês $(0,88)>$ óxido de ferro amorfo $(0,86)>$ óxido de ferro cristalino $(0,39)$.

Com a calagem, que el evou o $\mathrm{pH}$ dos solos para valores próximos a 7,0, não houve dessorção de Zn em nenhum solo ou dose utilizada, provavelmente em decorrência da drástica diminuição dos teores trocáveis, preci pitação de Zn em compostos de baixa solubilidade e aumento da adsorção específica do elemento, como sugere Barrow (1985).

Quanto à calagem, é importante observar que, em $\mathrm{pH}$ mais el evado, a maior parte do $\mathrm{Zn}$ em solução encontra-seem forma compl exada, com apenas uma pequena proporção presente na forma iônica livre, a qual poderia ser adsorvida pela resina. A forma iônica é predominante em solução em $\mathrm{pH}$ abaixo de 6,0 , mas acima desse valor a quantidade de $\mathrm{Zn}^{2+}$ decresce acentuadamente (Sanders, 1983). Esses dados reforçam os resultados obtidos nestetrabalho quanto à dessor ção desses el ementos pela resina, a qual é dependente da presença do el emento em sua forma iônica livre. 
Quadro 4. Coeficientes de correlação linear simples entre os teores de zinco por Mehlich-1, Mehlich-3, DTPA e EDTA e as frações: trocável, matéria orgânica, óxido de manganês, óxido de ferro amorfo, óxido de ferro cristalino, residual e teor total de amostras de seis solos, com (C/C) e sem calagem $(\mathbf{S} / \mathrm{C})$

\begin{tabular}{|c|c|c|c|c|c|c|c|c|}
\hline Extrator & Calagem & $\operatorname{Tr}$ & MO & OxMn & OxFeA & OxFeC & $\mathbf{R}$ & $\mathbf{T}$ \\
\hline$M-1$ & $\begin{array}{l}\mathrm{S} / \mathrm{C} \\
\mathrm{C} / \mathrm{C}\end{array}$ & $\begin{array}{l}0,95^{* *} \\
0,64^{* *}\end{array}$ & $\begin{array}{l}0,79 * * \\
0,94 * *\end{array}$ & $\begin{array}{l}0,84^{* *} \\
0,74 * *\end{array}$ & $\begin{array}{l}0,65^{* *} \\
0,53^{* *}\end{array}$ & $\begin{array}{l}0,22 \text { Ns } \\
0,47 * *\end{array}$ & $\begin{array}{r}-0,04 \text { NS } \\
0,02 \text { NS }\end{array}$ & $\begin{array}{l}0,49 * * \\
0,44^{* *}\end{array}$ \\
\hline$M-3$ & $\begin{array}{l}\mathrm{S} / \mathrm{C} \\
\mathrm{C} / \mathrm{C}\end{array}$ & $\begin{array}{l}0,95^{* *} \\
0,65^{* *}\end{array}$ & $\begin{array}{l}0,74 * * \\
0,96 * *\end{array}$ & $\begin{array}{l}0,80^{* *} \\
0,66^{* *}\end{array}$ & $\begin{array}{l}0,60^{* *} \\
0,75^{* *}\end{array}$ & $\begin{array}{l}0,24 \text { NS } \\
0,63^{* *}\end{array}$ & $\begin{array}{l}-0,09 \text { NS } \\
-0,03 \text { NS }\end{array}$ & $\begin{array}{l}0,42^{* *} \\
0,43^{* *}\end{array}$ \\
\hline DTPA & $\begin{array}{l}\mathrm{S} / \mathrm{C} \\
\mathrm{C} / \mathrm{C}\end{array}$ & $\begin{array}{l}0,92^{* *} \\
0,75^{* *}\end{array}$ & $\begin{array}{l}0,65 * * \\
0,89 * *\end{array}$ & $\begin{array}{l}0,72 * * \\
0,66^{* *}\end{array}$ & $\begin{array}{l}0,49 * * \\
0,75^{* *}\end{array}$ & $\begin{array}{l}0,18^{\text {NS }} \\
0,63^{* *}\end{array}$ & $\begin{array}{l}-0,05 \text { NS } \\
-0,03 \text { NS }\end{array}$ & $\begin{array}{l}0,42^{* *} \\
0,43^{* *}\end{array}$ \\
\hline EDTA & $\begin{array}{l}\mathrm{S} / \mathrm{C} \\
\mathrm{C} / \mathrm{C}\end{array}$ & $\begin{array}{l}0,96 * * \\
0,60^{* *}\end{array}$ & $\begin{array}{l}0,77^{* *} \\
0,93^{* *}\end{array}$ & $\begin{array}{l}0,81^{* *} \\
0,65^{* *}\end{array}$ & $\begin{array}{l}0,63^{* *} \\
0,65^{* *}\end{array}$ & $\begin{array}{l}0,17 \text { Ns } \\
0,52^{* *}\end{array}$ & $\begin{array}{l}-0,06 \text { NS } \\
-0,03 \text { NS }\end{array}$ & $\begin{array}{l}0,47 * * \\
0,40 * *\end{array}$ \\
\hline
\end{tabular}

*; **e NS: Significativos a 5 e 1 \%, respectivamente e não-significativo.
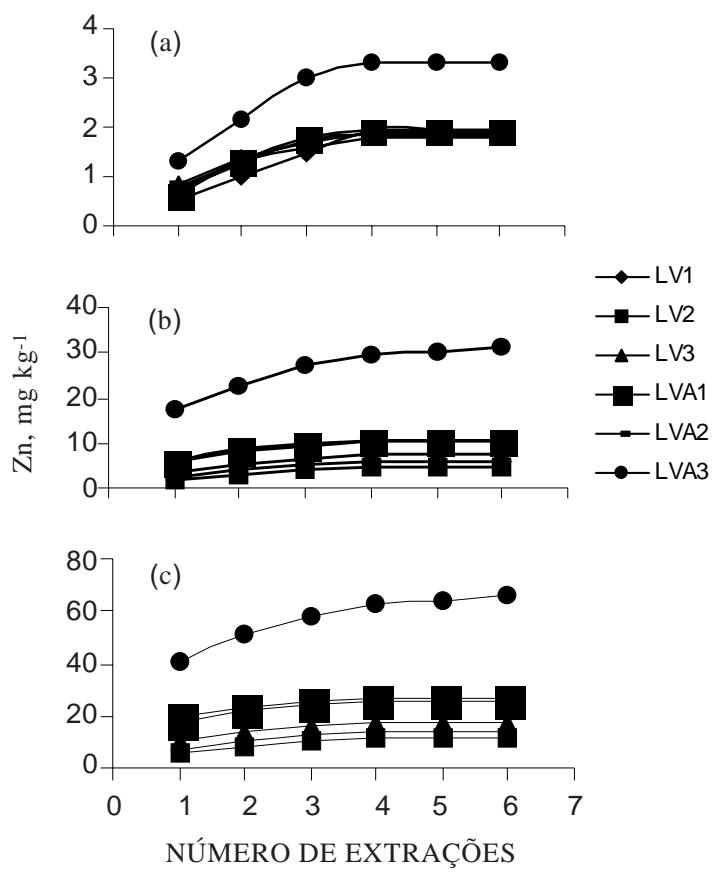

Figura 1. Dessorção cumulativa de zinco, em extrações sucessivas com resina de troca catiônica, em seis solos sem calagem e com 0,0 (a), 20 (b) e 40 (c) $\mathrm{mg} \mathrm{dm}^{-3} \mathrm{de} \mathrm{Zn.}$

\section{CONCLUSÕES}

1. O Zn aplicado foi retido, principalmente, nas frações: trocável e matéria orgânica. A calagem reduziu os teores de $\mathrm{Zn}$ na fração trocável e aumentou nas frações: matéria orgânica, óxidos de ferro amorfo e óxidos de manganês.

2. Nos solos sem calagem, o Zn trocável foi altamente correlacionado com os extratores Mehlich-1,
Mehlich-3, DTPA e EDTA. Nos sol os com calagem, todos os extratores apresentaram el evada correl ação com o Zn na fração orgânica.

3. Nos solos sem calagem, os teores de Zn dessorvidos das frações decresceram na seguinte ordem: trocável = matéria orgânica > óxido de manganês > óxido de ferro amorfo >>óxido de ferro cristalino. Os extratores EDTA, Mehlich-1 e Mehlich-3 apresentaram as melhores correlações com ototal dessorvido. A cal agem provocou ausência de dessorção para o Zn.

\section{LITERATURA CITADA}

ABREU, C.A. \& RAIJ , B. van. Efeito da reação do solo no zinco extraído pelas soluções de DTPA e Mehlich-1. In: CONGRESSO BRASILEIRO DE CIÊNCIA DO SOLO, 26., Rio de J aneiro, 1997. Anais. Rio de J aneiro, Sociedade Brasileira de Ciência do Solo, 1997. (CD-ROM).

ALLOWAY, B.J. The origins of heavy metals in soils. In: ALLOWAY, B.J ., ed. Heavy metals in soils. New York, J ohn Wiley \& Sons, 1990. p.29-39.

ALVAREZ V., V.H.; NOVAIS, R.F.; DIAS, L.E.\& OLIVEIRA, J.A. Determinação e uso do fósforo remanescente. B. Inf. SBCS, 25:21-32, 2000

BARROW, N.J . Reaction of anions and cations with variablecharge soils. Adv. Agron., 38:183-230, 1985.

BARROW, N.J . Mechanisms of reaction of zinc with soil and soil components. In: ROBSON, A.D, ed. Zinc in soils and plants. Dordrecht, Kluwer Academic Publishers, 1993. p.15-31.

BATAGLIA, O.C. \& RAIJ, B. van. Soluções extratoras na avaliação da fitodisponibilidade do zinco em solos. R. Bras. Ci. Solo, 18:457-461, 1994.

BORGGAARD, O.K. Selective extraction of amorphous iron oxides by EDTA from a Danish sandy loam. J. Soil Sci., 30:727-734, 1979. 
CAVALLARO, N. \& McBRIDE, M.B. Zinc and copper sorption and fixation by an acid soil clay: effect of selective dissolutions. Soil Sci. Soci. Am. J., 48:1050-1054, 1984.

CHAO, T.T. \& ZHOU, L. Extraction techniques for selective dissolution of amorphous iron oxides from soils and sediments. Soil Sci. Soci. Am. J., 47:224-232, 1983.

De FILIPPO, B.V. \& RIBEIRO, A.C. Análise química do solo. Metodologia. 2.ed. Viçosa, Universidade Federal deViçosa, 1997. $26 \mathrm{p}$.

EMPRESA BRASILEIRA DE PESQUISA AGROPECUÁRIA EMBRAPA. Manual de métodos de análise de solo. 2.ed. Rio deJ aneiro, Centro Nacional de Pesquisa de Solos, 1997. 212p.

HARTER, R.D. Micronutrient adsorption-desorption reactions in soils. In: MORTVERDT, J .J .; COX, F.R.; SHUMAN, L.M. \& WELCH, R.M., eds. Micronutrients in the agriculture, Madison, Soil Science Society of America, 1991. p.59-88.

IYENGAR, S.S.; MARTENS, D.C. \& MILLER, W.P. Distribution and plant availability of zinc soil fractions. Soil Sci. Soc. Am. J., 45:735-739, 1981.

J EFFREY, J J . \& UREN, N.C. Copper and zinc species in the soil solution and the effects of soil pH. Aust. J. Soil Res., 21:479488, 1983.

LANTMANN, A.F. \& MEURER, E.J. Estudo da eficiência de extratores para avaliação do zinco disponível do solo para o milho. R. Bras. Ci. Solo, 6:131-135, 1982.

LeCLAIRE, J.P.; CHANG, A.C.; LEVESQUE, C.S. \& SPOSITO, G. Trace metal chemistry and arid-zone field soils amended with sewage-sludge: IV. Correlation between zinc uptake and soil zinc fractions. Soil Sci. Soc. Am. J., 48:509-513, 1984.

LINDSAY, W.L. \& NORVELL, W.A. Development of a DTPA soil test for zinc, iron, manganese and copper. Soil Sci. Soc. Am. J., 42:421-428, 1978.

MA, Y.B. \& UREN, N.C. The fate and transformations of zinc added to soils. Aust. J. Soil Res., 35:727-738, 1997.

McBRIDE, M.B. Environmental chemistry of soils. New York, Oxford University Press, 1994. 406p.

MEHLICH, A. Mehlich-3 soil test extractant: a modification of Mehlich-2 extractant. Comm. Soil Sci. Plant Anal., 15:1409-1416, 1984.
MENEZES, A.A. Disponibilidade de zinco, para milho, pelos extratores Mehlich-1, Mehlich-3 e DTPA. Viçosa, Universidade Federal de Viçosa, 1998. 147p. (Tese de Mestrado)

NARWAL, R.P. \& SINGH, B.R. Effect of organic materials on partitioning, extractability and plant uptake of metals in alumi shale soil. Water, Air Soil Poll., 103:405-421, 1998.

OKAZAKI, M.; TAKAMIDOH, K. \& YAMANE, I. Adsorption of heavy metal cations on hydrated oxides and oxides of iron and aluminum with different crystallinities. Soil Sci. Plant Nutr., 3:523-533, 1986.

OLIVEIRA, M.G.; NOVAIS, R.F.; NEVES, J.C.L.; VASCONCELOS, C.A. \& ALVES, V.M. Relação entreozinco "disponível", por diferentes extratores, eas frações de zinco em amostras de solos. R. Bras. Ci. Solo 23:827-836, 1999.

SANDERS, J.R. The effects of $\mathrm{pH}$ on the total and free ionic concentrations of manganese, zinc and cobalt in soil solutions. J. Soil Sci., 34:315-323, 1983.

SHUMAN, L.M. Fractionation method for soil microelements. Soil Sci., 140:11-22, 1985.

SHUMAN, L.M. Effect of organic matter on the distribution of manganese, copper, iron, and zinc in soil fractions. Soil Sci., 146:192-198, 1988.

SIMS, J .L. \& PATRICK, W.H. The distribution of micronutrient cations in soil under conditions os varying redox potential and pH. Soil Sci. Soc. Am. J., 42:258-262, 1978.

SIMS, J.T. Soil pH effects on the distribution and plant availability of manganese, copper, iron and zinc. Soil Sci. Soc. Am. J., 50:367-373, 1986.

STEVENSON, F.J . Micronutrients soil tests. In: MORTVEDT, J.J .; COX, F.R.; SHUMAN, L.M. \& WELCH, R.M., eds. Micronutrients in agriculture. Madison, Soil ScienceSociety of America, 1991. p.427-472.

URE, A.M. Methods of analysis for heavy metals in soils. In: ALLOWAY, B.J. Heavy Metals in Soils. New York, J ohn Wiley \& Sons, 1990. p.40-80.

XIANG, H.F.; TANG, H.A. \& YING, Q.H. Transformation and distribution of forms of zinc in acid, neutral and calcareous soils of China. Geoderma, 66:121-135, 1995.

ZHU, B. \& ALVA, A.K. The chemical forms of $\mathrm{Zn}$ and $\mathrm{Cu}$ extractable by Mehlich-1, Mehlich-3, and ammonium bicarbonate-DTPA extractions. Soil Sci., 156:251-258, 1993. 